INTERNATIONAL FINANCIAL REPORTING STANDARDS IFRS: VIEWPOINTS AND APPROARCHING OF COUNTRIES ALL OVER THE WORLD

Tran Le Thi Bich Hong ${ }^{*}$, Nguyen Thi Nga $^{2}$

${ }^{I} T N U$ - University of Agriculture and Forestry

${ }^{2} T N U$ - University of Economics and Business Administration

\begin{tabular}{|c|c|c|}
\hline \multicolumn{2}{|c|}{ ARTICLE INFO } & \multirow{3}{*}{$\begin{array}{l}\text { ABSTRACT } \\
\text { This paper reviews the literature on International Financial Reporting } \\
\text { Standards (IFRS) adoption. The authors adopt a structured literature } \\
\text { review methodology. The article aims to explore the different }\end{array}$} \\
\hline Received: & $/ 10 / 20$ & \\
\hline Revised: & $10 / 1$ & \\
\hline Publis & 10 & approaches and perspectives currently being used by empirical studies \\
\hline & & \\
\hline \multicolumn{2}{|l|}{ KEYWORDS } & ieve this goal, an overview study of the scope, objec \\
\hline \multicolumn{2}{|l|}{ Financial statements } & conducted. As \\
\hline \multicolumn{2}{|c|}{$\begin{array}{l}\text { International financial reporting } \\
\text { standards }\end{array}$} & $\begin{array}{l}\text { it is shown that the success of IFRS as an international accounting } \\
\text { standard depends partly on its technical quality, bringing economic }\end{array}$ \\
\hline \multicolumn{2}{|l|}{ IFRS } & h plan users and makers of financial statements and on \\
\hline \multicolumn{2}{|l|}{ Application of IFRS } & . \\
\hline
\end{tabular}

Impact of IFRS

\title{
CHUẦN MỰC BÁO CÁO TÀI CHÍNH QUỐC TẾ IFRS: QUAN ĐIỂM VÀ CÁCH TIẾP CẬN CỦA CÁC QUỐC GIA TRÊN THẾ GIỚI
}

Trần Lệ Thị Bích Hồng ${ }^{1 *}$, Nguyễn Thị Nga ${ }^{2}$

${ }^{1}$ Truò̀ng Đại học Nông Lâm - ĐH Thái Nguyên

${ }^{2}$ Trưòng Đại học Kinh tế và Quản trị kinh doanh-ĐH Thái Nguyên

\begin{tabular}{|c|c|}
\hline THÔNC & U \\
\hline Ngày n & \multirow{11}{*}{ 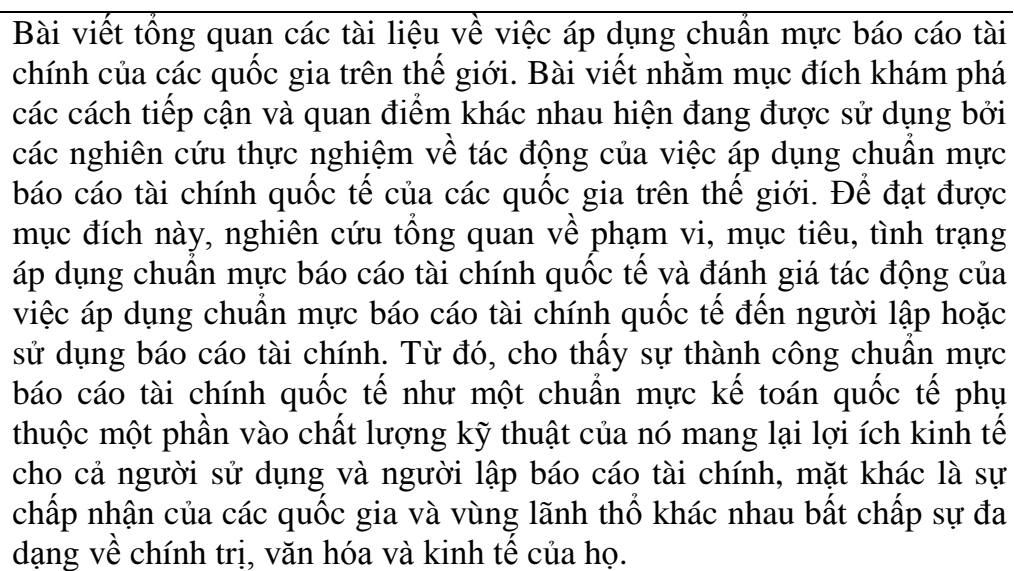 } \\
\hline & \\
\hline Ngày hoàn thiện: $10 / 1$ & \\
\hline Ngày đăng: $10 /$ & \\
\hline & \\
\hline TÙ' KF & \\
\hline Báo cá & \\
\hline $\begin{array}{l}\text { luấn mực báo cáo tài chínl } \\
\text { lốc tế }\end{array}$ & \\
\hline $\mathrm{RS}$ & \\
\hline dụng Il & \\
\hline & \\
\hline
\end{tabular}

DOI: $\underline{\text { https://doi.org/10.34238/tnu-jst.5192 }}$

* Corresponding author. Email: tranthibichhong@tuaf.edu.vn 


\section{1. Đặt vấn đề}

Chuẩn mực Báo cáo tài chính (BCTC) quốc tế (IFRS) cung cấp một khuôn khổ quốc tế về cách lập và trình bày $\mathrm{BCTC}$ cho các công ty đại chúng. IFRS tập trung hướng dẫn, diễn giải chung nhất về cách lập BCTC. Theo khái niệm của Hội đồng chuẩn mực Kế toán quốc tế (IASB), khuôn khổ lập và trình bày báo cáo tài chính đều có mục đích chung là cung cấp thông tin tài chính hữu ích cho các nhà đầu tư hiện tại và tiềm năng, chủ nợ, nhà cung cấp. Như vậy, mục tiêu của báo cáo tài chính chủ yếu được xây dựng trên tính hữu ích của thông tin ra quyết định. Báo cáo tài chính dự kiến sẽ giúp các bên liên quan có cái nhìn đúng đắn và khách quan về doanh nghiệp. Do vậy, ý tưởng sử dụng một chuẩn mực báo cáo tài chính duy nhất, toàn cầu được kế toán và các nhà đầu tư hết sức ủng hộ. Việc có các chuẩn mực thống nhất về kế toán sẽ giúp giảm thiểu chi phí cung cấp thông tin bổ sung cho người sử dụng thông tin tài chính [1]. Để giảm bớt sự khác biệt về chuẩn mực kế toán giữa các quốc gia, Ủy ban Chuẩn mực Kế toán quốc tế (IASC) được thành lập vào năm 1973 bởi các cơ quan kế toán chuyên nghiệp của 10 quốc gia gồm Australia, Canada, Pháp, Đức, Nhật Bản, Mexico, Hà Lan, Vương quốc Anh, Ireland và Hoa Kỳ [2]. Mục đích chính là giảm sự mâu thuẫn trong các nguyên tắc kế toán quốc tế và thông lệ báo cáo. Các chuẩn mực do IASC soạn thảo và ban hành được gọi là Chuẩn mực Kế toán Quốc tế (IAS). Vào tháng 4 năm 2001, IASB thiết lập các chuẩn mực kế toán quốc tế, được gọi là Chuẩn mực báo cáo tài chính Quốc tế (IFRS) [1]. Mục đích chính của IFRS là nâng cao tính minh bạch, củng cố trách nhiệm giải trình và đóng góp vào hiệu quả kinh tế của báo cáo tài chính [3]. Do đó, IFRS đưa ra các nguyên tắc về ghi nhận, đo lường, trình bày và công bố thông tin quá đó giúp báo cáo tài chính của doanh nghiệp phản ánh thực tế tình hình kinh tế tài chính và cung cấp thông tin đáng tin cậy và trung thực [4]. Các công trình nghiên cứu đã công bố trên thế giới chủ yếu tập trung vào nghiên cứu tác động của việc áp dụng IFRS đến chất lượng, thông tin ra quyết định, tính hữu ích và khả năng so sánh giữa các doanh nghiệp của báo cáo tài chính.

Các quốc gia trên thế giới quyết định hội tụ với IFRS nhằm mục đích chính là cải thiện khả năng so sánh giữa các báo cáo tài chính trên toàn thế giới [5]. Việc so sánh các báo cáo tài chính cho phép người sử dụng so sánh tình hình hoạt động tài chính và vị trí của một công ty với các công ty khác tương tự và so sánh với chính công ty đó trong quá khứ. Trước năm 2005, các công ty áp dụng các nguyên tắc kế toán chung được thừa nhận theo từng quốc gia cụ thể (GAAP) [6]. Sự phù hợp của các chuẩn mực kế toán quốc tế đã loại bỏ hoặc giảm đáng kể sự đa dạng của GAAP trên các nước khác nhau. Hiện nay, đã có hơn 156 quốc gia trên thể giới thực hiện việc yêu cầu (bắt buộc) hoặc cho phép (không bắt buộc) các công ty niêm yết trên thị truờng chứng khoán của họ sử dụng IAS/IFRS khi lập và trình bày BCTC. Qua các nghiên cứu đã công bố cho thấy có ít bằng chứng chỉ ra tính chất có thể so sánh được của báo cáo tài chính có ảnh hưởng đến thị trường vốn nhưng lại có sự thay đổi đáng kể trong chất lượng cáo cáo tài chính và hiệu quả kinh tế giữa các quốc gia khi áp dụng IFRS. Nguyên nhân chính là do có sự khác biệt cố hữu trong nền kinh tế, môi trường pháp lý mà các doanh nghiệp đang hoạt động [7]. Do đó, tuy có nhiều quốc gia đã hội tụ với IFRS nhưng vẫn có sự khác biệt nhất định trong quá trình áp dụng hệ thống IFRS [8]. Bài viết nhằm tổng quan các nội dung về phạm vi của IFRS, thực trạng áp dụng và quan điểm tiếp cận IFRS của các quốc gia trên thế giới từ đó xác định những tác động của phương pháp tiếp cận IFRS đến lợi ích của người lập/sử dụng báo cáo tài chính.

\section{Phương pháp nghiên cứu}

Cơ sở dữ liệu được sử dụng trong nghiên cứu này là số liệu thứ cấp, được thu thập từ các tài liệu, các tạp chí, các báo cáo, các website chuyên ngành về tình hình và lợi ích của việc áp dụng IFRS.

Phương pháp nghiên cứu chủ đạo là phương pháp nghiên cứu tại bàn (Desk Research) để xử lý và phân tích các thông tin thứ cấp thu thập được. Quá trình nghiên cứu được thực hiện như sau:

- Phương pháp phân loại lý thuyết: Nhóm tác giả tiến hành sắp xếp các tài liệu thứ cấp liên quan đến IFRS thành các nhóm tài liệu về hình thành và phát triển IFRS; mức độ hòa hợp của 
IAS/IFRS, mức độ hội tụ kế toán; thực trạng áp dụng IFRS của một số quốc gia trên thế giới; tác động của việc áp dụng IFRS đến lợi ích của người lập và sử dụng báo cáo tài chính.

- Phương pháp hệ thống hóa lý thuyết: Sắp xếp những thông tin đa dạng thu thập được từ các nhóm tài liệu được phân loại ở trên thành một hệ thống thông tin thứ cấp có liên quan chặt chẽ để từ đó giúp người đọc hiểu biết về IFRS được đầy đủ và sâu sắc hơn.

\section{Kết quả nghiên cứu}

\subsection{Phạm vi của IFRS}

IFRS quy định việc ghi nhận, đo lường, trình bày và các yêu cầu công bố thông tin liên quan đến giao dịch và sự kiện quan trọng của các doanh nghiệp theo định hướng lợi nhuận. Phạm vi của IFRS được áp dụng cho tất cả các doanh nghiệp thương mại, sản xuất, tài chính và các hoạt động khác, cho mọi loại hình công ty. IFRS không được thiết kế cho khu vực công và các tổ chức phi chính phủ, tuy nhiên các tổ chức này vẫn có thể vận dụng được một số nội dung IFRS phù hợp nhưng phải có các tiêu chuẩn kế toán quốc tế tùy chỉnh cho khu vực này. Hội đồng chuẩn mực kế toán khu vực công quốc tế (IPSASB) đang xây dựng các chuẩn mực kế toán công dựa trên IFRS.

Mục tiêu của IASB trong việc thiết lập IFRS được xác định trong sáu khía cạnh: (i) Tiêu chuẩn chung: Mục tiêu chính của IASB là phát triển, vì lợi ích công cộng, xây dựng một bộ tiêu chuẩn kế toán toàn cầu chất lượng cao, dễ hiểu và có thể thực thi; (ii) Sự tín nhiệm: Việc áp dụng IFRS dẫn đến chất lượng thông tin được cung cấp bởi báo cáo tài chính được nâng cao và minh bạch; (iii) Khả năng so sánh: IFRS giúp cho việc so sánh báo cáo tài chính ở các quốc gia khác nhau có thể thực hiện; (iv) Tuân thủ: IASB cố gắng thúc đẩy việc sử dụng và áp dụng chặt chẽ IFRS; (v) Tùy chỉnh: Để thực hiện các mục tiêu trên, IASB sẽ tính đến sự phù hợp về nhu cầu đặc biệt là các tổ chức có qui mô nhỏ và vừa ở các nước đang phát triển và (vi) Sự hội tụ: nhằm mang lại sự hòa hợp, hội tụ của các chuẩn mực kế toán quốc gia và IFRS để đề xuất các giải pháp phù hợp cho việc áp dụng IFRS. IFRS được xây dựng dựa trên các nguyên tắc trong khi chuẩn mực kế toán tại các quốc gia chủ yếu được dựa trên quy tắc. Cấu trúc dựa trên nguyên tắc giúp cho IFRS đủ tính linh hoạt để có thể áp dụng ở cấp độ toàn thế giới.

\subsection{Anh hưởng của phương pháp tiếp cận IFRS đến lọi ích của ngưòi lập/sủ dụng báo cáo tài chính}

Việc ngày càng có nhiều quốc gia trên thế giới áp dụng IFRS đã thúc đẩy một số các nghiên cứu kiểm tra tác động của việc áp dụng chuẩn mực này đến tính hữu ích, mức độ liên quan và lợi ích. Hai yếu tố quan trọng để làm cho IFRS được coi là chuẩn mực kế toán toàn cầu, cũng là một mục tiêu của IASB trong việc thiết lập IFRS là việc áp dụng IFRS có "lợi ích ròng" và liệu lợi ích đó có phổ biến hay không bất kể chính trị, kinh tế và sự đa dạng văn hóa giữa các quốc gia dự kiến sẽ áp dụng IFRS. Đoạn 44 của Khung khái niệm đối với việc lập và trình bày báo cáo tài chính cho rằng "Lợi ích thu được từ thông tin nên vượt quá chi phí cung cấp thông tin". Tuy nhiên, việc đánh giá các lợi ích và chi phí về cơ bản là một sự đánh giá tiến trình. Hơn nữa, người chịu chi phí không nhất thiết phải là người tận hưởng những lợi ích. Những lợi ích cũng có thể được dành cho cả những người dùng khác với những người mà thông tin được chuẩn bị cho; ví dụ, việc cung cấp thêm thông tin cho người cho vay có thể giảm chi phí đi vay của một đơn vị. Vì những lý do này, rất khó để áp dụng kiểm tra chi phí - lợi ích trong bất kỳ trường hợp cụ thể nào. Tuy nhiên, những người thiết lập chuẩn mực, cũng như người lập và người sử dụng báo cáo tài chính, phải nhận thức được ràng buộc này. Do đó, có thể nhóm lợi ích của việc áp dụng IFRS thành hai nhóm chính là nhóm lợi ích đối với người sử dụng báo cáo tài chính (lợi ích của người dùng) và nhóm lợi ích đối với đơn vị báo cáo (lợi ích công ty). Các nhà đầu tư là người sử dụng chính của báo cáo tài chính và họ được cho là có lợi từ IFRS bằng cách thu thập thông tin liên quan để đưa ra các quyết định kinh tế. Tuy nhiên, việc mang lại lợi ích này sẽ không làm cho IFRS được chấp nhận rộng rãi trong thời gian dài trừ khi công ty phải chịu chi phí thực hiện 
chúng (cả chi phí rõ ràng và chi phí tiềm ẩn) ít nhất là sự cân bằng. Do đó, việc đạt được cả hai loại lợi ích (nghĩa là lợi ích của người dùng và lợi ích của doanh nghiệp) là điều quan trọng để nhận ra các mục tiêu của IFRS.

Lambertides và Mazouz cũng nhóm các nghiên cứu áp dụng IFRS thành hai khía cạnh chính dựa trên lợi ích của việc áp dụng IFRS trong đó đầu tiên tập trung vào "chất lượng thông tin" có thể tạo thành" lợi ích của người dùng "và thứ hai là việc thực hiện" giảm chi phí vốn "có xu hướng đại diện cho" lợi ích công ty". Với luồng nghiên cứu đầu tiên cho thấy rằng việc tiết lộ theo các chuẩn mực IFRS sẽ cung cấp chất lượng thông tin cao hơn cho các nhà đầu tư bên ngoài so với các chế độ kế toán trong nước. Luồng nghiên cứu thứ hai tuyên bố rằng các công ty có mức độ công khai thông tin nhiều hơn sẽ làm giảm sự bất cân xứng thông tin giữa nhóm các nhà đầu tư khác nhau, từ đó tăng tính thanh khoản và giảm chi phí vốn [12].

Các nghiên cứu IFRS tìm cách điều tra tác động đến lợi ích của người dùng thường sử dụng các khái niệm về mức độ liên quan của giá trị trong thông tin kế toán, quản lý thu nhập, lỗi dự báo thu nhập của nhà phân tích,... để điều tra xem báo cáo tài chính và các thông tin khác được công bố theo các chuẩn mực dựa trên IFRS hữu ích hơn cho các quyết định kinh tế của các nhà đầu tư, những người sử dụng chính báo cáo tài chính. Sự thành công của IFRS với tư cách là một chuẩn mực kế toán quốc tế phụ thuộc vào sự phong phú về kỹ thuật và sự chấp nhận ở các quốc gia khác nhau bất chấp sự đa dạng về chính trị, văn hóa và kinh tế. Về mặt kỹ thuật, IFRS quy định việc ghi nhận, đo lường, trình bày và công bố thông tin yêu cầu đối với các giao dịch và sự kiện quan trọng trong báo cáo tài chính. Các yêu cầu công nhận và đo lường của IFRS trực tiếp liên quan đến "số liệu kế toán" trong khi các yêu cầu về trình bày và thuyết minh thường liên quan đến "tiết lộ" giúp thông tin kế toán phù hợp hơn với việc ra quyết định. Người dùng có thể được hưởng lợi từ báo cáo tuân thủ IFRS để thông tin tài chính trở nên đáng tin cậy hơn, có thể so sánh được và nhiều thông tin hữu ích hơn để đưa ra các quyết định kinh tế của họ. Do đó, các khía cạnh kỹ thuật mà các nghiên cứu thực nghiệm IFRS tập trung có thể được tóm tắt và được mô tả như trong Hình 1.

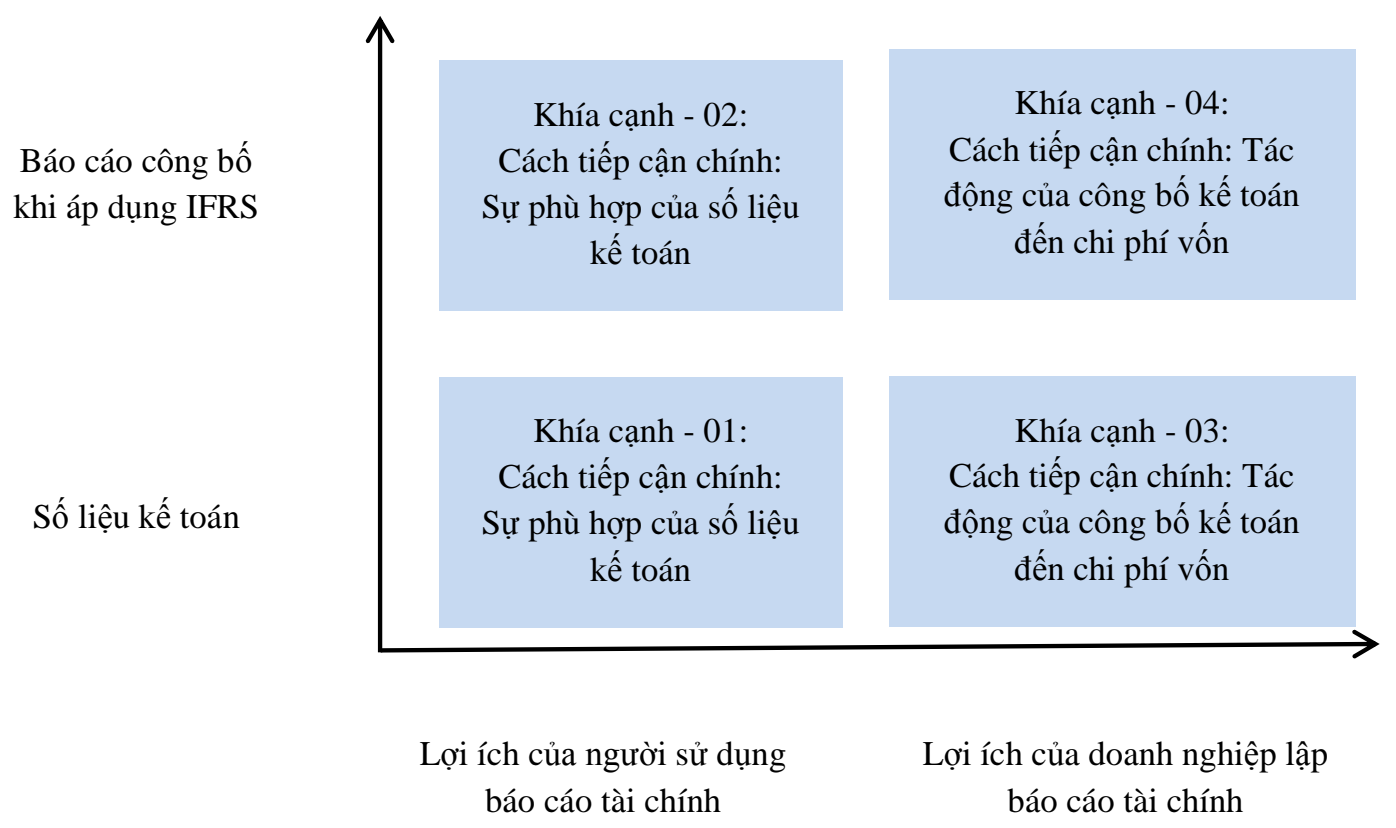

Hình 1. Bốn khía cạnh bị tác động bởi IFRS

Nhiều nghiên cứu đã sử dụng khái niệm giá trị liên quan của thông tin kế toán để xem xét tác động của IFRS. Mức độ liên quan về giá trị của thông tin kế toán cho biết mức độ thông tin kế toán giải thích giá cổ phiếu hoặc lợi tức cổ phiếu và do đó giá trị của các công ty. Bên cạnh đó, 
khái niệm quản lý thu nhập/chất lượng thu nhập, độ chính xác của dự báo thu nhập của các nhà phân tích cũng có được sử dụng rộng rãi để đánh giá lợi ích của người dùng khi áp dụng IFRS. Các nghiên cứu rơi vào khía cạnh - 02 khi đánh giá giá trị mức độ liên quan của các thông tin được công bố (hoặc/cả công bố tự nguyện và bắt buộc) liên quan đến việc áp dụng IFRS. Bên cạnh đó, một góc nhìn khác để xem tác động của IFRS được xây dựng dựa trên tính quốc tế của nó. Nếu IFRS thực sự trở thành các chuẩn mực kế toán quốc tế, các tác động trên của IFRS phải được thể hiện rõ trong các quốc gia trên toàn cầu không phân biệt sự đa dạng về chính trị, kinh tế và văn hóa.

\subsection{Kinh nghiệm tiếp cận IFRS của các quốc gia trên thế giới và ở Việt Nam}

Các quốc gia trên thế giới đang ngày càng quan tâm và áp dụng IFRS một cách đầy đủ hoặc có sự sửa đổi cần thiết để các báo cáo tài chính của các tổ chức của từng quốc gia được chấp nhận rộng rãi và có thể so sánh được với báo cáo tài chính trên toàn cầu. Hiện nay, trên thế giới có 144 quốc gia (chiếm 86,8\%) áp dụng IFRS cho hầu hết các công ty cổ phần niêm yết trên thị trường chứng khoán và các tổ chức tài chính bắt buộc phải công khai thông tin, 86 quốc gia (chiếm $52 \%$ ) quốc gia yêu cầu hoặc cho phép áp dụng IFRS đối với khối doanh nghiệp có qui mô vừa và nhỏ.

Bảng 1. Tình trạng áp dụng IFRS trên thế giới

\begin{tabular}{ccccc}
\hline Vùng & $\begin{array}{c}\text { Tổng số quốc } \\
\text { gia của Vùng }\end{array}$ & $\begin{array}{c}\text { Quốc gia bắt buộc } \\
\text { áp dụng IFRS cho } \\
\text { đơn vị có lọi ích } \\
\text { công chúng }\end{array}$ & $\begin{array}{c}\text { Quốc gia cho phép } \\
\text { lựa chọn áp dụng } \\
\text { IFRS cho đơn vị có } \\
\text { lọi ích công chúng }\end{array}$ & $\begin{array}{c}\text { Aụng chuẩn mực } \\
\text { báo cáo tài chính } \\
\text { riêng của quốc gia, } \\
\text { không áp dụng IFRS }\end{array}$ \\
\hline Châu Âu & 44 & 43 & 1 & 0 \\
Châu Phi & 38 & 36 & 1 & 1 \\
Trung Đông & 13 & 13 & 0 & 0 \\
Châu Á - & 34 & 25 & 3 & 7 \\
Châu Đại Dương & 37 & 27 & 8 & 2 \\
Châu Mỹ & $\mathbf{1 6 6}$ & $\mathbf{1 4 4}$ & $\mathbf{1 2}$ & $\mathbf{1 0}$ \\
Tổng số & $\mathbf{1 0 0 \%}$ & $\mathbf{8 6 , 8 \%}$ & $\mathbf{7 , 2 \%}$ & $\mathbf{6 \%}$ \\
Tỷ lệ \% & &
\end{tabular}

(Nguồn: Phân tích hồ so của IFRS và IASB)

(*) Các công ty niêm yết trên thị trường chứng khoán và tổ chức tài chính trên thị trường vốn.

Theo số liệu thống kê ở bảng 1 cho thấy, IFRS ngày càng được áp dụng phổ biến ở nhiều khu vực, nhiều quốc gia và nhiều tổ chức quốc tế. Tổng GDP của các quốc gia áp dụng IFRS là 41 nghìn tỷ USD, bằng hơn một nửa GDP toàn thế giới. Mặc dù Liên minh Châu Âu là khu vực có số quốc gia áp dụng IFRS nhiều nhất với 43 quốc gia bắt buộc áp dụng IFRS cho đơn vị có lợi ích công chúng, 01 quốc gia cho phép lựa chọn áp dụng IFRS cho đơn vị có lợi ích công chúng và không có quốc gia nào áp dụng chuẩn mực kế toán riêng nhưng tổng GDP của các nước áp dụng IFRS bên ngoài EU (24 nghìn tỷ USD) lớn hơn quốc gia trong EU (17 nghìn tỷ USD). Các tổ chức quốc tế hiện nay áp dụng IFRS gồm G20, ngân hàng thế giới, quỹ tiền tệ quốc tế, Ưy ban Basel (ủy ban liên hiệp các cơ quan giám sát nghiệp vụ ngân hàng tại 12 quốc gia công nghiệp lớn), Liên đoàn kế toán quốc tế.

Mặc dù có nhiều nghiên cứu tin rằng việc áp dụng IFRS dẫn đến nhiều lợi thế hơn, nhưng vẫn có nhiều quan điểm ngược lại cho rằng các chuẩn mực kế toán thống nhất sẽ không phải là lựa chọn phù hợp với điều kiện kinh tế có sự khác biệt đáng kể giữa các quốc gia. Các chuẩn mực kế toán thống nhất là một điều tách biệt với việc đạt được sự đồng nhất trong thực tế do sự khác nhau về chính trị và thị trường ở các quốc gia [9]. Do đó, có vẻ như sẽ có sự khác biệt trong việc thực thi các chuẩn mực kế toán, từ quốc gia này sang quốc gia khác, điều này dẫn đến rất khó để kỳ vọng rằng các báo cáo tài chính từ các công ty ở các nơi trên thế giới có thể so sánh được với nhau. Do đó, trong những năm qua, việc lập báo cáo tài chính có thể thay đổi căn bản trên toàn thế giới đã là trung tâm của nhiều cuộc tranh luận về chính sách công. IFRS cải thiện khả năng so 
sánh của các báo cáo tài chính giữa các quốc gia, do đó mang lại hiệu quả cao hơn cho báo cáo của các doanh nghiệp ở các quốc gia khác nhau.

Căn cứ vào thực trạng áp dụng IFRS của các quốc gia trên thế giới cho thấy việc áp dụng chuẩn mực kế toán riêng của từng quốc gia ngày càng bị thu hẹp lại, việc chuyển đổi sang áp dụng IFRS ngày càng trở nên phổ biến hơn. Tuy nhiên, quan điểm tiếp cận IFRS của các quốc gia cũng khác nhau. Về cơ bản, có thể thấy có những quan điểm tiếp cận IFRS như sau:

Tiếp cận trực tiếp: Quốc gia đó sẽ sử dụng IFRS làm chuẩn mực kế toán trong nước. Do đó, những thay đổi trong IFRS sẽ có hiệu lực tại quốc gia kể từ ngày thực hiện những thay đổi đó trong IFRS. Tuy nhiên, trên thực tế cách tiếp cận này không phổ biến ở các nước ở giai đoạn này và có thể kỳ vọng vào một nền kinh tế toàn cầu hội nhập hơn trong tương lai.

Áp dụng hoàn toàn: Có sự hội tụ chuẩn mực kế toán trong nước với IFRS. Các chuẩn mực kế toán trong nước sẽ được áp dụng đầy đủ theo các nguyên tắc của IFRS. Cách tiếp cận này là tạm thời phổ biến trên toàn cầu với khoảng 144 quốc gia và vùng lãnh thổ đã áp dụng IFRS, chiếm $87 \%$.

Áp dụng một phần: Các quốc gia tiếp cận theo cách này nghĩa là sẽ tiệm cận một phần IFRS vào chuẩn mực kế toán trong nước hoặc IFRS được áp dụng cho một vài tổ chức chịu trách nhiệm giải trình công khai (không phải tất cả các tổ chức chịu trách nhiệm công khai đều yêu cầu báo cáo dựa trên IFRS).

Cho phép lựa chọn: Tại một số quốc gia có cả IFRS và các chuẩn mực kế toán trong nước. IFRS đã được thông qua, thường cách tiếp cận này tồn tại ở các nước đang trong quá trình chuyển đổi sang IFRS.

Thông thường quan điểm áp dụng IFRS của các quốc gia trên thế giới sẽ được thực hiện theo một lộ trình, bắt đầu từ việc cho phép lựa chọn đến áp dụng một phần và áp dụng hoàn toàn. Một số quốc gia điển hình ở châu Á đã thành công với lộ trình áp dụng IFRS gồm:

Hàn Quốc: là quốc gia điển hình đã triển khai thành công IFRS theo cách tiếp cận áp dụng hoàn toàn sau 04 năm kể từ lúc lộ trình áp dụng IFRS được công bố. Năm 2016, Hàn Quốc đã đánh giá các tác động từ việc áp dụng K-IFRS, và cho thấy các tác động tích cực đến từ các hoạt động tài trợ quốc tế cho các công ty tại Hàn Quốc.

Singapore: Kể từ năm 2002, Singapore ban hành chuẩn mực BCTC của Singapore (SFRS) dựa trên cơ sở IFRS, áp dụng cho các doanh nghiệp niêm yết trên sàn giao dịch Singapore. Nhìn chung, Singapore đã có quá trình xem xét để áp dụng IFRS khá dài từ năm 2002 đến 2014. Trong giai đoạn này, Singapore chưa áp dụng hoàn toàn IFRS ngay, mà có những sửa đổi phù hợp và chỉ áp dụng trước cho những doanh nghiệp niêm yết, sau đó mới áp dụng cho những doanh nghiệp khác. Hiện nay, Singapore đang sử dụng Chuẩn mực BCTC Singapore, dù không tương đương $100 \%$ với IFRS nhưng vẫn là một con số ở mức độ tương đương đáng kể $(95 \%)$. Vì vậy, việc áp dụng toàn bộ IFRS sẽ không phải là một trở ngại quá lớn đối với Singapore trong tương lai.

Thái Lan: Năm 2006, Liên đoàn Kế toán Quốc tế (FAP) và Ủy ban Chứng khoán Thái Lan đã ký cam kết về việc tuân thủ chuẩn mực kế toán quốc tế và tuân thủ theo IFRS. Năm 2007, Thái Lan ban hành các Chuẩn mực Kế toán áp dụng cho các doanh nghiệp không phải là doanh nghiệp đại chúng như là các doanh nghiệp tư nhân. Trong hai năm 2008 - 2009, Thái Lan có động thái xúc tiến quá trình chuyển đổi như ban hành nhiều văn bản hướng dẫn sử dụng khuôn khổ kế toán mới, điều chỉnh CMKT theo IFRS và đặt tên là TFRS. FAP lên kế hoạch thực hiện áp dụng IFRS chặng đầu tiên từ 2011 khi Sở Giao dịch Chứng khoán Thái Lan (SET) thúc đẩy đối tượng tiên phong thực hiện tuân thủ theo IFRS là 50 doanh nghiệp đại chúng

Cách tiếp cận và áp dụng IFRS ở các quốc gia là khác nhau, song lộ trình và các bước tiến hành đều mang lại những kinh nghiệm tốt cho Việt Nam. Theo kinh nghiệm của một số nước trên thế giới Việt Nam cần lưu ý một số điểm sau:

Trong giai đoạn đầu thực hiện áp dụng IFRS ở Việt Nam nên khoanh vùng các đối tượng ưu tiên thực hiện, trước hết chỉ áp dụng với những công ty có vốn đầu tư nước ngoài, công ty đại chúng có niềm yết, ngân hàng và tổ chức tài chính. 
Nhờ tư vấn của chuyên gia từ các nước có kinh nghiệm thực hiện IFRS để tư vấn cho các doanh nghiệp áp dụng IFRS ở Việt Nam.

Nâng cao hệ thống kết nối thông tin và phần mềm kế toán cho các doanh nghiệp.

Nâng cao trình độ năng lực chuyên môn cho những cán bộ làm IFRS.

Việt Nam áp dụng IFRS là rất cần thiết, nhằm nâng cao tính so sánh, tính minh bạch của thông tin công bố và thể hiện trách nhiệm của các nhà quản trị trong việc phản ánh trung thực trạng thái tài chính của doanh nghiệp.

Khi áp dụng IFRS ở Việt Nam sẽ đạt được những hiệu quả nhu:

Các báo cáo tài chính được lập ra dựa trên chuẩn mực phạm vi mang tính toàn cầu và đáng tin cậy.

Khi công bố báo cáo tài chính theo IFRS, các doanh nghiệp (DN) Việt Nam thấy được lợi ích từ việc hội nhập kinh tế quốc tế, cụ thể về việc huy động nguồn vốn, duy trì năng lực cạnh tranh và phát triển một cách bền vững;

IFRS là một ngôn ngữ chung cho các con số trên BCTC của tất cả các DN tham gia hoạt động tại thị trường kinh tế toàn cầu. Vì vậy, doanh nghiệp Việt Nam cũng sẽ trở thành một thành viên tham gia trong hệ thống này khi được các nhà đầu tư quốc tế công nhận, đồng thời là con đường thuận lợi để tiếp cận nguồn vốn quốc tế.

\section{Kết luận}

Lập BCTC theo IFRS ngày càng nhận được sự ủng hộ của các quốc gia và vùng lãnh thổ trên thế giới. IFRS được cho là sẽ cải thiện chất lượng và khả năng so sánh của báo cáo tài chính. Tổng quan các nghiên cứu cho thấy tác động của việc áp dụng IFRS đến lợi ích của người dùng thường sử dụng các khái niệm về mức độ liên quan của giá trị thông tin kế toán, quản lý thu nhập, dự báo thu nhập của nhà phân tích,... để điều tra liệu báo cáo tài chính và các thông tin khác được công bố theo các chuẩn mực dựa trên IFRS có nhiều hữu ích hơn cho việc ra quyết định kinh tế của các nhà đầu tư, những người sử dụng báo cáo tài chính. Dựa trên đánh giá trong nghiên cứu này đã kết luận rằng sự thành công của IFRS với tư cách là một chuẩn mực kế toán quốc tế phụ thuộc một mặt là chất lượng kỹ thuật của nó mang lại hiệu quả kinh tế cho cả người sử dụng và người báo cáo tài chính, mặt khác các tuyên bố và sự chấp nhận áp dụng IFRS ở các quốc gia và vùng lãnh thổ khác nhau không kể sự đa dạng về chính trị, văn hóa và kinh tế.

Việt Nam trong quá trình hội nhập, cũng nhận thức được sự cần thiết phải áp dụng IFRS cũng như những lợi ích và khó khăn mà quá trình áp dụng IFRS mang lại. Tuy nhiên trong quá trình thực hiện IFRS, Việt Nam cần thực hiện lộ trình một cách vững chắc để việc áp dụng IFRS được thuận lợi, nhanh chóng và đạt kết quả tốt. Một số kinh nghiệm quý giá và phù hợp có thể được áp dụng tại Việt Nam khi áp dụng IFRS là cần lựa chọn một số loại hình công ty như công ty có vốn nước ngoài, công ty đại chúng có niêm yết, khối các tổ chức ngành tài chính tín dụng, bảo hiểm, các tập đoàn và tổng công ty lớn của Nhà nước để bắt đầu thực hiện.

\section{TÀI LIÊU THAM KHẢO/ REFERENCES}

[1] A. Madawaki, "Adoption of international financial reporting standards in developing countries: The case of Nigeria," International Journal of Business and Management, vol. 7, no. 3, p. 152, 2012.

[2] R. Ball and D. Damant, "International Financial Reporting Standards (IFRS): pros and cons for investors/Discussion," Accounting and Business Research, vol. 5, no. 27, pp. 29-30, 2006.

[3] IFRS Foundation, "Who We Are and What We Do: Retrieved from London, United Kingdom," 2016. [Online]. Available: http://www.ifrs.org. [Accessed September 12, 2021].

[4] UK, "True and Fair Accounting and Reporting, Financial Reporting Council, The Financial Reporting Council Limited,” 2014. [Online]. Available: http://www.frc.org.uk. [Accessed September 14, 2021].

[5] L. Hail, C. Leuz, and P. Wysocki, "Global Accounting Convergence and the Potential Adoption of IFRS by the U.S. (Part I): Conceptual Underpinnings and Economic Analysis," Accounting Horizons, vol. 24, no. 3, pp. 355-394, 2010.

[6] N. Soderstrom and K. Sun, "IFRS adoption and accounting quality: A review," European Accounting Review, vol. 16, pp. 675-702, 2007. 
[7] G. De Franco, S. Kothari, and R. Verdi, “The benefits of financial statement comparability," Journal of Accounting Research, no. 49, pp. 895-931, 2011.

[8] N. Apergis, C. Christou, and C. Hassapis, "Accounting standards convergence dynamics - International evidence from club convergence and clustering," Accounting Research Journal, vol. 27 no. 3, pp. 133, 2014.

[9] R. Ball, "International financial reporting standards (IFRS): pros and cons for investors," Accounting and Business Research, vol. 36, pp. 5-27, 2006.

[10] V. M. Covrig, M. L. DeFond, and M. Hung, "Home bias, Foreign mutual fund holdings, and the voluntary adoption of international accounting standards," Journal of Accounting Research, vol. 45 no. 1, pp. 41-70, 2007.

[11] M. E. Barth, W. R. Landsman, and M. H. Lang, "International accounting standards and accounting quality," Journal of Accounting Research, vol. 46, no. 3, pp. 467-98, 2008.

[12] N. Lambertides and K. Mazouz, "Stock price volatility and informational efficiency following the mandatory adoption of IFRS in Europe," Journal of Applied Accounting Research, vol. 14, no. 1, pp. 4-17, 2013. 